\title{
BMJ Open Response strategies for promoting gender equality in public health emergencies: a rapid scoping review
}

\author{
Janina I Steinert (10 , ${ }^{1,2}$ Caterina Alacevich, ${ }^{3}$ Bridget Steele, ${ }^{2}$ Julie Hennegan,,${ }^{4,5}$ \\ Alexa R Yakubovich ${ }^{6}$
}

To cite: Steinert Jl, Alacevich C, Steele B, et al. Response strategies for promoting gender equality in public health emergencies: a rapid scoping review. BMJ Open 2021;11:e048292. doi:10.1136/ bmjopen-2020-048292

- Prepublication history and additional supplemental material for this paper are available online. To view these files, please visit the journal online. (http://dx.doi.org/10.1136/ bmjopen-2020-048292)

Received 22 December 2020 Accepted 26 July 2021

\section{Check for updates}

(C) Author(s) (or their employer(s)) 2021. Re-use permitted under CC BY-NC. No commercial re-use. See rights and permissions. Published by BMJ.

${ }^{1}$ TUM Schoool of Governance, Technical University of Munich, München, Germany

${ }^{2}$ Department of Social Policy and Intervention, University of Oxford, Oxford, UK

${ }^{3}$ Nuffield Department of Primary Care Health Sciences, University of Oxford, Oxford, UK

${ }^{4}$ Maternal, Child and Adolescent Health Program, Burnet Institute, Melbourne, Victoria, Australia

${ }^{5}$ Melbourne School of Population and Global Health, University of Melbourne, Melbourne, Victoria, Australia

${ }^{6}$ MAP Centre for Urban Health Solutions, St Michael's Hospital, Unity Health Toronto, University of Toronto, Toronto, Ontario, Canada

Correspondence to Dr Janina I Steinert; janina.steinert@tum.de

\section{ABSTRACT}

Objectives The COVID-19 pandemic threatens to widen existing gender inequities worldwide. A growing body of literature assesses the harmful consequences of public health emergencies (PHEs) for women and girls; however, evidence of what works to alleviate such impacts is limited. To inform viable mitigation strategies, we reviewed the evidence on gender-based interventions implemented in PHEs, including disease outbreaks and natural disasters. Methods We conducted a rapid scoping review to identify eligible studies by systematically searching the databases MEDLINE, Global Health and Web of Science with the latest search update on 28 May 2021. We used the Sustainable Development Goals as a guiding framework to identify eligible outcomes of gender (in)equality.

Results Out of 13920 records, 16 studies met our eligibility criteria. These included experimental (3), cohort (2), case-control (3) and cross-sectional (9) studies conducted in the context of natural disasters (earthquakes, droughts and storms) or epidemics (Zika, Ebola and COVID-19). Six studies were implemented in Asia, seven in North/Central America and three in Africa. Interventions included economic empowerment programmes (5); health promotion, largely focused on reproductive health (10); and a postearthquake resettlement programme (1). Included studies assessed gender-based outcomes in the domains of sexual and reproductive health, equal opportunities, access to economic resources, violence and health. There was a dearth of evidence for other outcome domains relevant to gender equity such as harmful practices, sanitation and hygiene practices, workplace discrimination and unpaid work. Economic empowerment interventions showed promise in promoting women's and girls' economic and educational opportunities as well as their sexual and reproductive health during PHEs. However, some programme beneficiaries may be at risk of experiencing unintended harms such as an increase in domestic violence. Focused reproductive health promotion may also be an effective strategy for supporting women's sexual and reproductive health, although additional experimental evidence is needed.

Conclusions This study identified critical evidence gaps to guide future research on approaches to alleviating gender inequities during PHEs. We further highlight that interventions to promote gender equity in PHEs should take into account possible harmful side effects such as increased gender-based violence.

Review registration DOI 10.17605/0SF.I0/8HKFD.

\section{Strengths and limitations of this study}

This is the first review to assess interventions and programmes to prevent or mitigate the impact of public health emergencies on gender inequality worldwide.

- This rapid scoping review points to important evidence gaps with regard to several Sustainable Development Goal indicators of gender inequality (eg, harmful practices, sanitation and hygiene, workplace discrimination and unpaid work).

- We considered only published studies and are thus unable to present insights that may emerge from reviewing grey literature.

- Our search was limited to research published in English, and findings published in other languages were therefore not synthesised.

- While we present evidence on the uptake of, impact of and engagement with interventions, we cannot draw conclusions on why and how a programme may work or not.

\section{INTRODUCTION}

The COVID-19 pandemic has resulted in several million deaths worldwide and has caused devastating socioeconomic disruptions. ${ }^{1}$ Emerging evidence shows that women and girls are likely to bear the brunt of the socioeconomic impacts of the pandemic and that COVID-19 has the potential to exacerbate existing gender inequalities. ${ }^{2-4}$ In light of this concern, this rapid scoping review aimed to identify interventions and policy strategies that can advance gender-equitable outcomes in the context of public health emergencies (PHEs). Given that the COVID-19 pandemic is currently ongoing, we adopted a broad perspective by drawing on scientific evidence from previous PHEs, including disease outbreaks, epidemics, pandemics and natural disasters, along with evidence generated in response to the pandemic to date (28 May 2021)..$^{5}$

The United Nations Sustainable Development Goal 5 (SDG5) aims to 'achieve 
gender equality and empower all women and girls'. SDG5 defines gender (in) equality according to different domains, including violence against women, access to sexual and reproductive health, access to water, sanitation and hygiene (WASH), educational and economic opportunities, exposure to harmful practices, as well as care and domestic work. A growing body of literature demonstrates the links between PHEs and gender inequities across these domains. First, existing studies point to a rise in violence against women and girls during PHEs. ${ }^{36-8}$ Empirical research has documented a higher prevalence of physical and sexual violence against women during the Ebola crisis in Sierra Leone, Liberia and the Gambia. ${ }^{9-12}$ Recent studies suggest that women and children were exposed to an increased risk of family violence during the COVID-19 lockdown. ${ }^{13-17}$ Plausible mechanisms include increased environmental and interpersonal stressors (eg, greater economic instability), the need to shelter in place with abusive partners or family members, and barriers in accessing services or social support. ${ }^{1819}$

Evidence from past PHEs has also highlighted detrimental impacts on women's sexual and reproductive health, largely as a result of the diversion of scarce healthcare resources and personnel to the immediate emergency response. ${ }^{20-22}$ These include excess rates of miscarriages during the 1918 influenza, ${ }^{23}$ higher odds of pregnancy-related mortality during the SARS and Middle East respiratory syndrome (MERS) epidemics, ${ }^{24}$ and excess maternal, neonatal and stillbirth deaths due to major cuts in antenatal care coverage. ${ }^{21}$ The COVID-19 pandemic has caused major disruptions in the supply chains for modern contraceptives in some low-income countries, ${ }^{25}$ which may elevate the risk of teenage pregnancies. Relatedly, during the Ebola crisis in West Africa, the rate of teenage pregnancies increased by $65 \%-75 \%{ }^{26}$

Further, PHEs can disrupt WASH services including the failure of maintenance or supply systems, ${ }^{27}$ and restrict access and availability of hygiene products such as soap and menstrual materials. Inadequate access to private, safe and clean WASH facilities can expose women to physical discomfort, shame and stigmatisation while menstruating, ${ }^{28}$ and constrain disease prevention efforts altogether. ${ }^{29}$ A lack of basic services can also mean that women have to travel long distances to fetch water, which increases women's unpaid workload while reducing the time spent on education or income generation. ${ }^{30}$

Particularly in low-resource settings, PHEs can thwart girls' educational opportunities and make them more vulnerable to harmful practices such as child marriage. In Sierra Leone, for instance, the school enrolment rate of girls dropped by 16 percentage points post-Ebola. ${ }^{31}$ School closures that were implemented to contain the spread of the coronavirus have affected more than 800 million girls to date ${ }^{32}$ There has been growing concern that this policy may ultimately widen gender gaps in education due to a higher load of household chores and caregiving work being assigned to girls, preventing them from studying. ${ }^{32}$ In addition, as PHEs can put enormous economic strains on low-income households, marrying off a daughter to receive a bride-price can become a survival strategy for some families. For instance, Corno and colleagues found that in sub-Saharan Africa, girls aged 12-17 years had a significantly higher likelihood of getting married if their household was affected by a drought. ${ }^{33}$

In addition, in high-income and low-income countries alike, women may face an increased informal care burden in the context of PHEs, either to look after family members who need daily assistance or who have fallen sick, ${ }^{34}$ or to look after their children, ${ }^{35}$ as was the case during the COVID-19 lockdowns. ${ }^{4}$ Increased care responsibility can thwart women's employment opportunities and amplify pre-existing biases in couples' division of paid and unpaid work. ${ }^{36}$ For instance, Sevilla and Smith found that during the first COVID-19 infection wave in the UK, mothers were taking a substantially larger share of the additional childcare hours per week compared with fathers. ${ }^{37}$ In addition, International Labour Organization estimates suggest that during the first months of the COVID-19 pandemic, informal workers across the world were facing an average of $60 \%$ cut in their incomes. ${ }^{38}$ Given that the informal sector employs disproportionally more women than men, ${ }^{39}$ women have been particularly vulnerable to loss of livelihoods. ${ }^{30}$

Lastly, the COVID-19 pandemic may disproportionately affect women's health risks. Although epidemiological evidence suggests that the COVID-19 infection and death rates are higher among men (Williamson et al, 2020 $0^{40}$, women make up $70 \%$ of the global front-line health workforce and may thus face a higher risk of contracting the virus. ${ }^{2041-43}$

In light of this evidence, it is clear that PHEsincluding the ongoing COVID-19 pandemic-are not gender-neutral. ${ }^{44}$ Applying a gender lens to interventions and policies implemented in the context of PHEs is therefore crucial. Despite the expansive literature on the detrimental effects of PHEs on women and girls, systematic evidence regarding which interventions can mitigate these impacts to date is scarce. To inform viable response strategies, we conducted a rapid scoping review of the existing evidence on the relationship between interventions implemented in past PHEs and gender equality goals. To our knowledge, this is the first comprehensive synthesis of the literature on the uptake, mechanisms and effects of PHE response programmes across the domains of gender equality.

\section{METHODS}

A review protocol specifying the search strategy and eligibility criteria was published via the Open Science Foundation on 24 April 2020. ${ }^{45}$ Our search and synthesis strategies were based on rapid review guidelines. ${ }^{46}$

\section{Search strategy}

We searched for published studies describing interventions and policies implemented in the context of PHEs that aimed 
to reduce gender inequality. We selected major health and social science databases to reflect the cross-disciplinary nature of the topic. We searched MEDLINE, Global Health and Web of Science between 28 April and 7 May 2020 and updated the search on 28 May 2021. Search terms were in English and categorised according to the concepts of (1) PHEs (covering search terms for pandemics, epidemics and natural disaster); (2) outcomes related to gender (in) equality (covering search terms for the following SDG aspects: women's and girls' discrimination, violence, harmful practices, unpaid work, equal opportunities, economic participation, WASH and sexual and reproductive health); and (3) interventions (see online supplemental appendix 1 for our search strategy). We hand-searched references of identified literature reviews for additional eligible studies.

\section{Inclusion criteria}

Studies were eligible if they reported on a gender-based intervention, policy or response strategy that was implemented in the context of a PHE. We defined PHEs as situations in which an imminent threat of harm to public health necessitates immediate and non-routine action, including disease outbreaks, epidemics, pandemics (eg, SARS, Zika, Ebola, etc) or natural disasters (eg, earthquakes, tsunamis, flooding, etc). ${ }^{5748}$ We excluded the HIV/AIDS pandemic, endemic diseases (eg, malaria) rather than rapid and acute emergencies, and human-made rather than exogeneous events (eg, the opioid crisis, humanitarian conflicts and terrorism), as we understood these to involve different mechanisms of impact and because we hypothesised that response strategies would need to be different. We also excluded vaccination and immunisation programmes as these interventions cannot be adequately transferred to the context of other PHEs. Lastly, we excluded programmes that were existing prior to pandemics and then continuously delivered throughout.

Our inclusion criteria required that studies reported on either gendered predictors of uptake of and engagement with (eg, use of and participation in) an active intervention or assessed associations between the intervention and outcomes related to gender (in)equality. To define these outcomes, we drew on the targets of the SDGs, specifically SDG5 on gender equality and other gender-relevant SDG targets (SDG3: health; SDG4: education; SDG6: WASH) (see box 1 for our outcomes framework).

This rapid scoping review excluded qualitative studies but did not apply any other restrictions with regard to the research design, considering that it might be unethical or unfeasible to conduct a randomised controlled trial during a PHE. No restrictions were made in terms of geographical setting of the intervention, participants' age or publication date.

\section{Study screening and data extraction}

After removing duplicates, we screened titles and abstracts. We first independently piloted our screening criteria on 200 records. Once we established $100 \%$ consistency in our decisions, we divided the remaining records
Box 1 Gender equality outcome framework (authors' elaboration)

- Discrimination of women and girls (eg, legal frameworks to promote non-discrimination and enacted/perceived gender attitudes/norms) (SDG 5.1).

- Violence against women and girls (eg, psychological, physical and sexual violence by an intimate partner or other person) (SDG 5.2).

- Harmful practices (eg, forced marriage and child marriage) (SDG 5.3).

- Recognition of unpaid domestic work and shared responsibility of domestic burdens (SDG 5.4).

- Equal opportunities in political, economic and public life (eg, girls' school enrolment rates and share of women in political/economic leadership roles) (SDG 5.5 and SDG 4.5).

- Women's and girls' sexual and reproductive health (eg, incidence of teenage pregnancies and use of modern contraceptives) (SDG 5.6 and SDG3.7).

- Maternal health (SDG 3.1).

- Equal rights to economic resources (eg, proportion of women in formal employment and access to financial services) (SDG 5.a).

- Women's and girls' access to information and communication technologies (SDG 5.b).

- Access to water, sanitation and hygiene for women and girls' specific health needs (eg, women's access to menstrual health and hygiene resources, etc) (SDG 6.2).

among all authors. We followed a similar process for full-text screening: we independently piloted $10 \%$ of all potentially eligible studies to establish consistency, then we divided screening among four authors. We extracted data from included studies using a piloted Excel form, including (1) type and country of PHE, (2) description of the intervention, (3) target population and sample size, (4) research design and (5) gender-related outcomes.

\section{Data synthesis}

We graphically synthesised data by categorising studies according to intervention type and mapped these against our gender inequality outcomes framework. We synthesised these data across three aspects of interventions, drawing on the Medical Research Council framework for evaluating complex interventions: (1) uptake and reach of the intervention; (2) implementation process of the intervention (eg, participant engagement and attendance); and (3) intervention effects. ${ }^{49}$ We classified intervention results as positive $(+)$ if estimates suggested that the intervention presented a positive association with gender equity outcomes; negative (-) if estimates suggested that the intervention presented a negative association; and neutral (0) if estimates were not conclusive (ie, a mix of positive, negative or null results). We made these determinations based on the direction and size of the point estimate and variability of the interval estimate, wherever available, as opposed to relying solely on statistical significance, in line with current best practice. ${ }^{50}{ }^{51}$ We critically appraised the quality of included studies according to the suitability of the research design for the research question, the representativeness of the sample, the quality of 


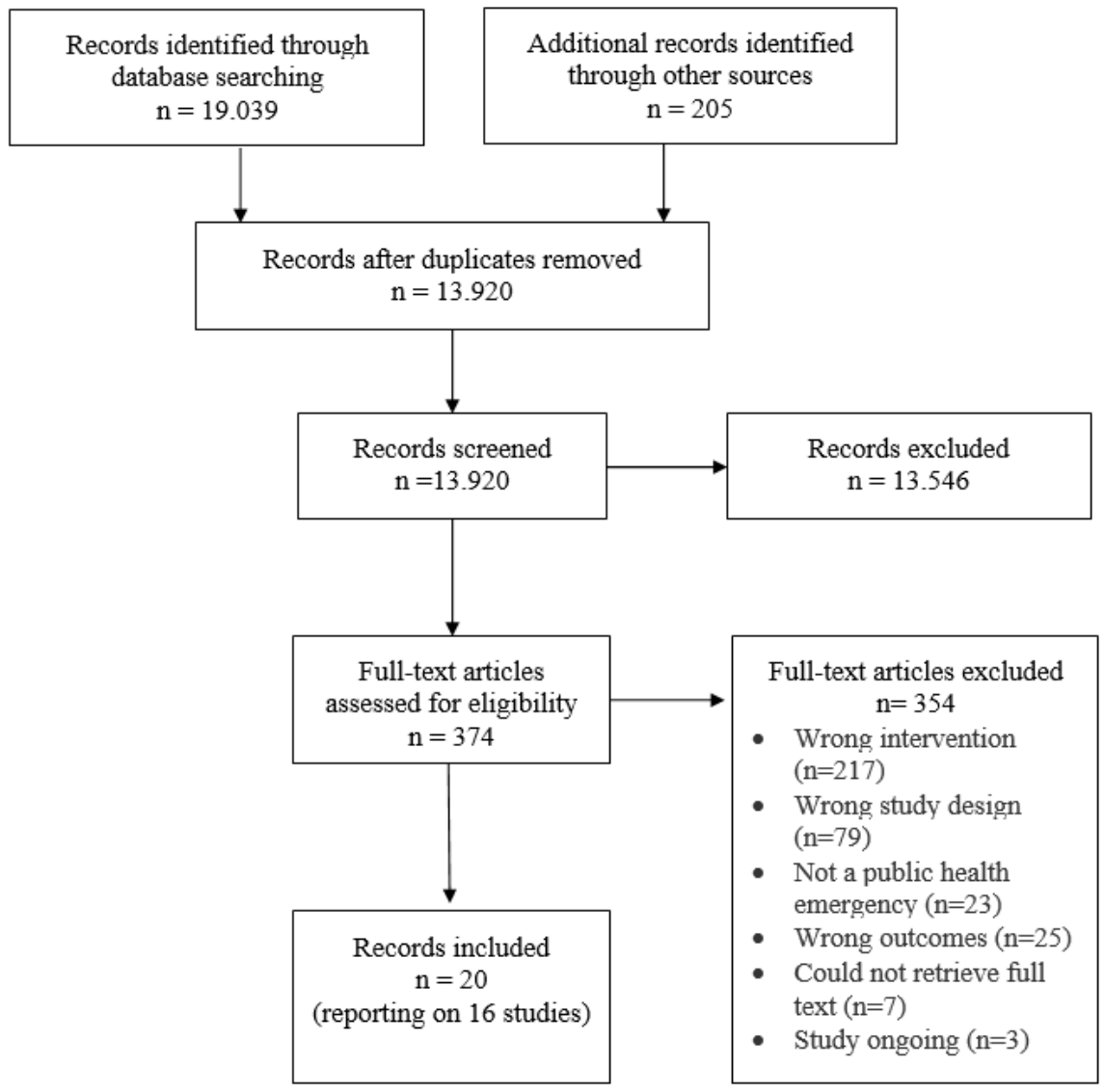

Figure 1 Review flowchart.

the measurement procedures, and the transparency and rigour of the applied statistical analyses.

\section{Patient and public involvement}

Patients (or in this case: emergency-affected populations) were not involved in the design or analysis stage of this study because we exclusively relied on secondary data from previously published articles. However, we intend to present results to relevant populations to involve them in the interpretation and dissemination of our research finding, as well as involve them in designing questions to ask in future studies.

\section{RESULTS}

\section{Included studies}

The database search returned 13920 unique articles after deduplication (see figure 1). We excluded 13546 studies after screening titles and abstracts. After screening 374 full texts, we excluded 353 because they reported on ineligible interventions $(61 \%)$, were qualitative $(22 \%)$, were not implemented in the context of a PHE (7\%), did not include gender-related outcomes $(7 \%)$, could not be retrieved in full text (2\%) or were currently ongoing $(1 \%)$. Twenty papers met the inclusion criteria, of which 4 reported on the same intervention, thus resulting in 16 stand-alone studies.

\section{Characteristics of included studies}

Geographical setting and PHE

Table 1 and figure 2 present an overview of the 16 included studies. Included studies were published between 2005 and 2021. The majority of interventions were implemented in low-income and middle-income countries, namely, in Ethiopia (2), India (2), Iran (1), Sierra Leone (1), Bangladesh (1), Nepal (1) and Turkey (1). Five interventions were implemented in the USA and three were implemented in Puerto Rico. Eight studies were implemented in the context of natural disasters, including storms (2), flooding (2), droughts (2) and earthquakes (2). The remaining studies reported on interventions carried out in the context of epidemics or a pandemic, namely, Ebola (1), Zika (3) and COVID-19 (4). Sample sizes varied considerably between studies, ranging from 96 pregnant women in the context of COVID- $19^{52}$ to evaluations using administrative data for 29221 women who received a reproductive health training programme in response to the Zika epidemic. ${ }^{53-55}$

\section{Intervention types}

The included studies covered interventions that can be broadly categorised into three types (see figures 2 and 3): (1) economic empowerment, (2) health promotion and (3) postdisaster resettlement. Five studies assessed economic empowerment interventions: three studies reported 


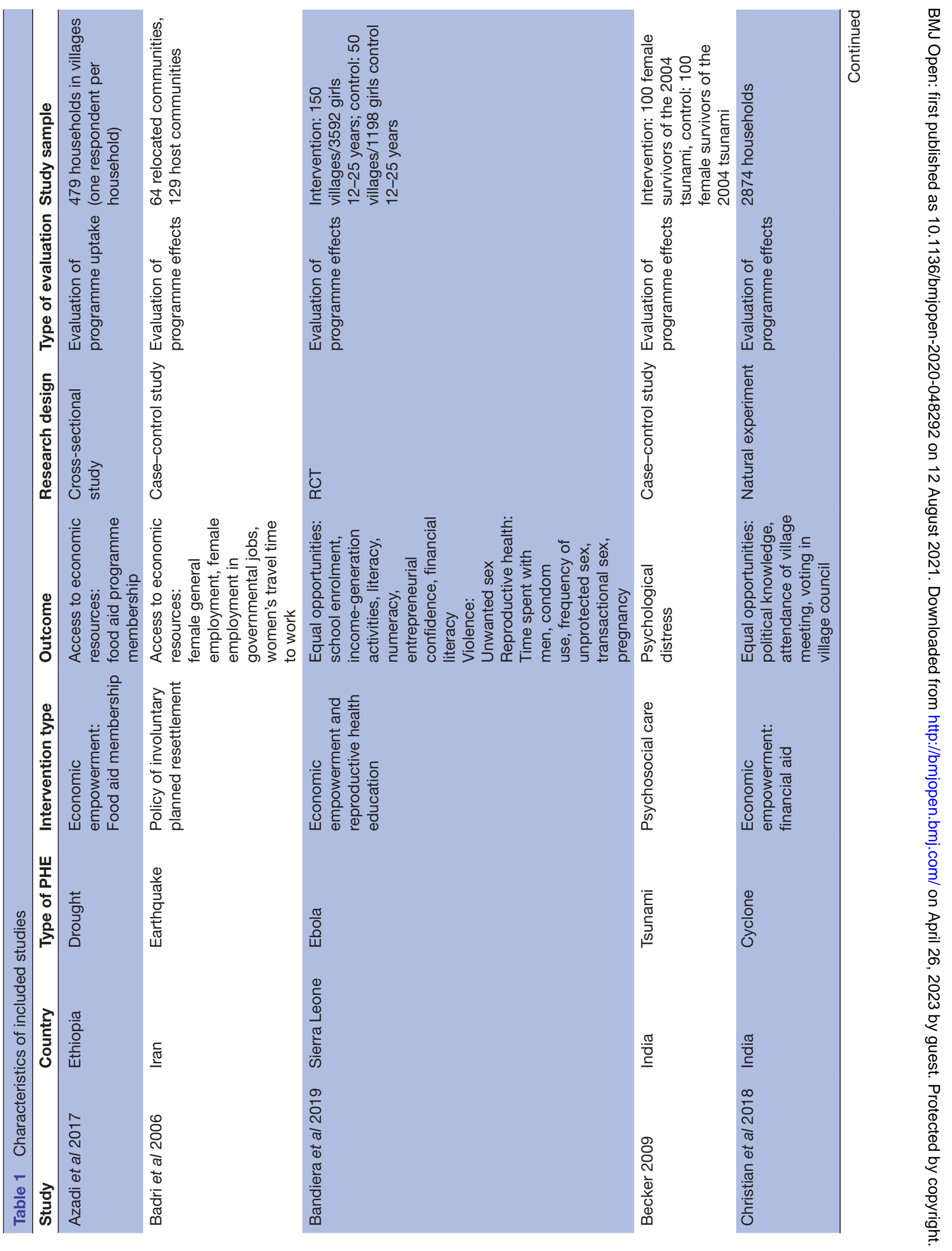




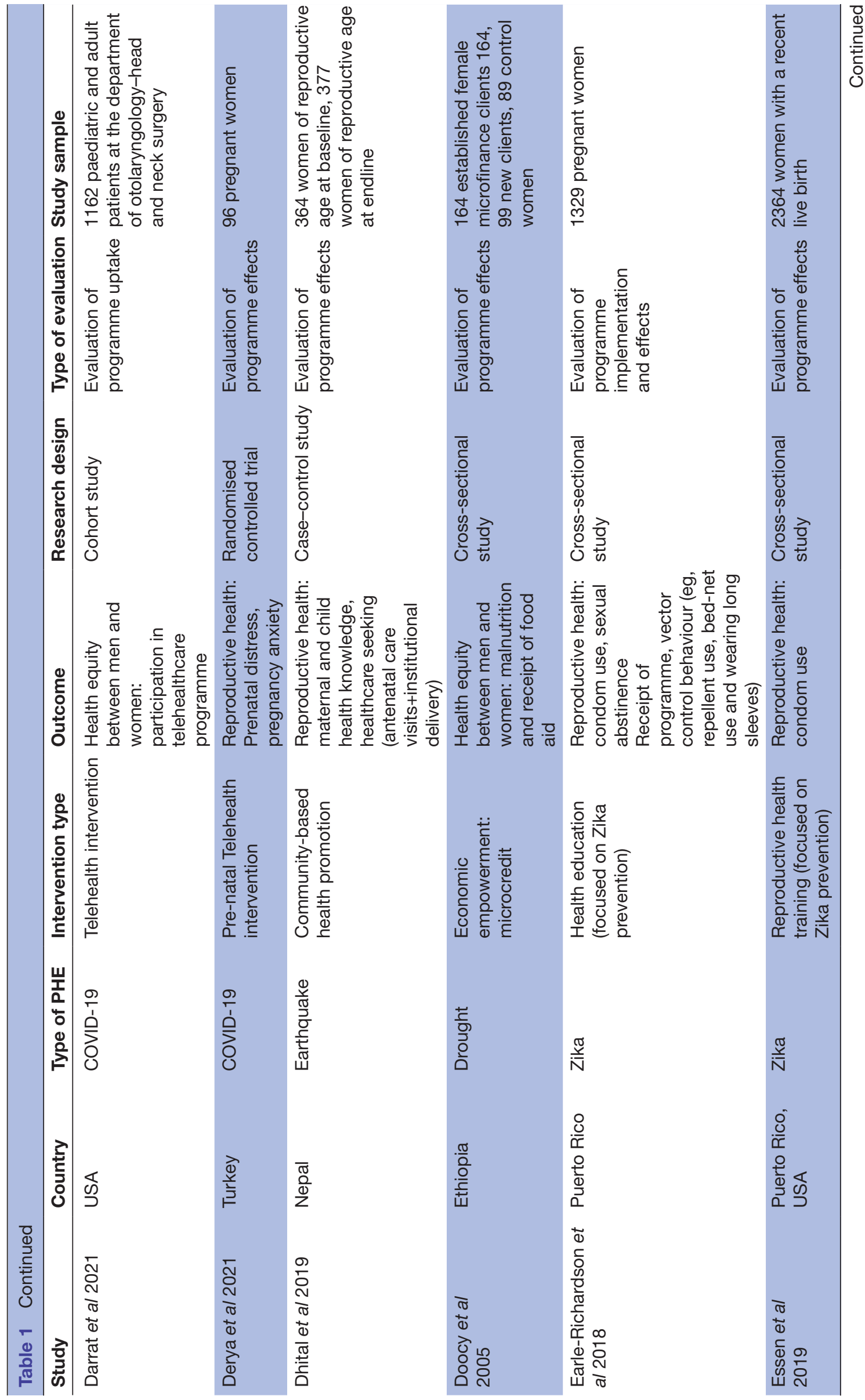

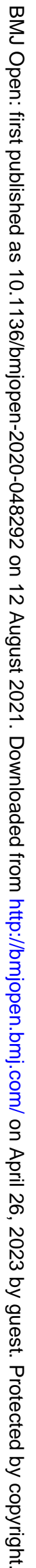




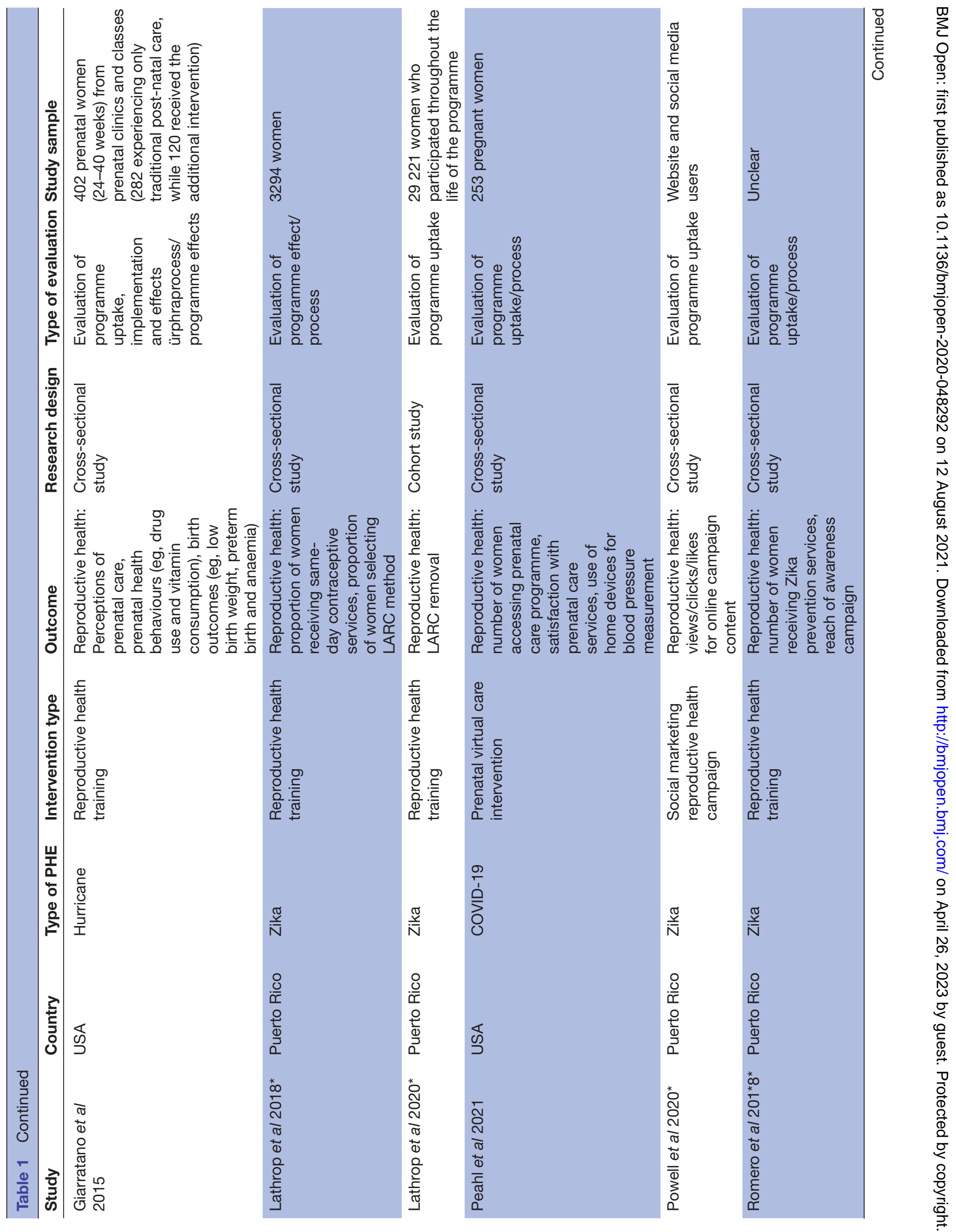




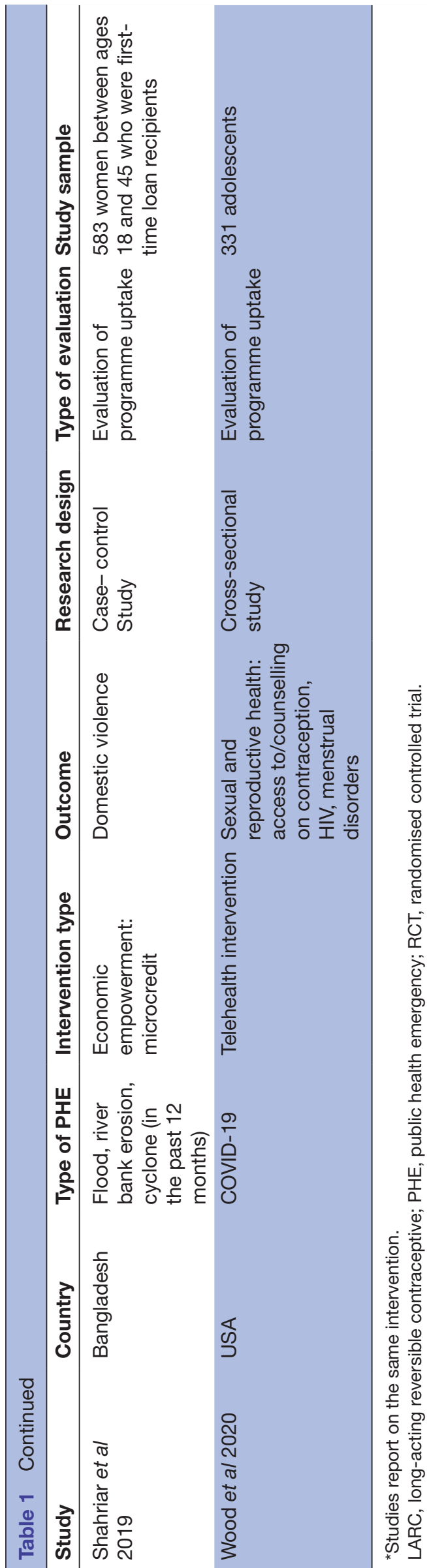

on microfinance interventions and financial aid (one cross-sectional, one case-control and one experimental study), ${ }^{56-58}$ and one cross-sectional study evaluated uptake of a food aid programme implemented in response to several major droughts in Ethiopia. ${ }^{59}$ The fifth study, a randomised controlled trial conducted by Bandiera $e t a l$, assessed the impact of a multicomponent intervention for young women and girls (aged 12-25 years) in the context of Ebola, featuring training on financial literacy and vocational skills, access to microfinance and other noneconomic programme components. ${ }^{31}$

The second broad intervention category was health promotion programmes, assessed in 10 studies. The majority of these programmes were focused on promoting women's reproductive health. One cross-sectional study described the New Orleans Healthy Start programme that was implemented shortly after Hurricane Katrina and aimed to improve prenatal care for pregnant women in communities with high infant mortality rates. ${ }^{60}$ Another case-control study reported on a community-based health promotion intervention to expand access to healthcare for Nepalese mothers that were severely affected by the 2015 earthquake. ${ }^{61}$ Three cross-sectional studies reported on Zika-focused interventions, including (1) reproductive health training and counselling, ${ }^{53-5562}$ (2) training of healthcare providers to increase the quality of contraceptive service provision, ${ }^{53-55}$ and (3) building of community awareness through a mass media campaign and distribution of Zika prevention kits. ${ }^{6364}$ Two cross-sectional studies, one cohort study and one randomised controlled trial presented virtual or telehealth health interventions that were implemented in the context of the COVID-19 pandemic. $^{52}{ }^{65-67}$ All but one of these were focused on reproductive health. One health promotion intervention evaluated a psychosocial care programme for female survivors of the tsunami in India in a case-control design. ${ }^{68}$

One case-control study reported on a unique intervention that fell in neither of the aforementioned two categories: a postdisaster resettlement programme implemented in response to the Manjil earthquake in Iran, which involved the relocation and integration of some hard-hit villages to nearby locations. ${ }^{69}$

\section{Gender equality outcomes}

Figure 3 displays the different outcome measures that were captured by included studies (see also table 1 for detailed information from each study). The figure highlights important gaps: several outcome domains remain fully unaddressed in the context of PHEs, including: (1) harmful practices such as child marriage, (2) WASH management, (3) unpaid work, (4) women's social discrimination and (5) women's access to information technology. It is further noteworthy that most assessed interventions (with the exception of Bandiera $e t a \hat{l}^{31}$ ) targeted only one gender equality domain.

The majority of included studies evaluated outcomes related to sexual and reproductive health: (1) (teenage) pregnancy; (2) access to and use of modern contraceptives; 


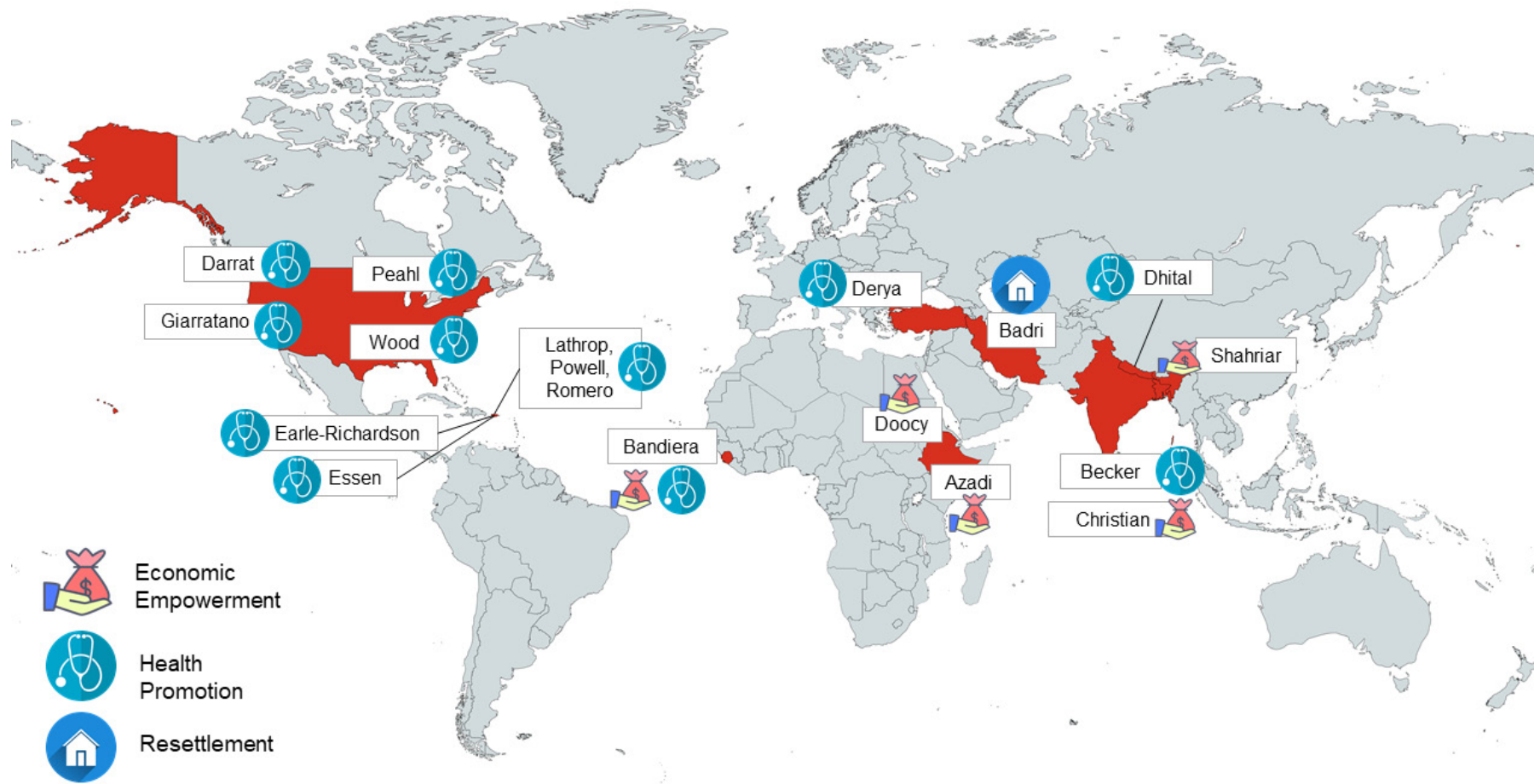

Figure 2 Geographical scope and intervention types of included studies.

(3) sexual risk behaviours (eg, unprotected, age-disparate sex and transactional sex); (4) access to and satisfaction with prenatal care; (5) prenatal distress and pregnancy anxiety; (6) reproductive healthcare counselling; and (7) menstrual disorders.

Four studies assessed aspects of health equity, including sex-disaggregated malnutrition indicators and receipt of food aid, ${ }^{70}$ women's psychological distress, ${ }^{68}$ women's use of telehealth services ${ }^{65}$ and women's adoption of preventative health behaviours. ${ }^{63}$ Two studies reported on dimensions of equal opportunities, specifically capturing girls' school enrolment, their numeracy and literacy levels, and the engagement of school-aged girls in income-generation activities (which can hamper their educational achievements), ${ }^{31}$ as well as women's civic and political engagement. ${ }^{71}$ Lastly, two studies assessed interventions on women's access to economic resources, specifically food aid membership uptake, ${ }^{59}$ female employment, ${ }^{69}$ and girls' financial literacy and entrepreneurial confidence, ${ }^{31}$ and two studies focused on genderbased violence. $^{3158}$

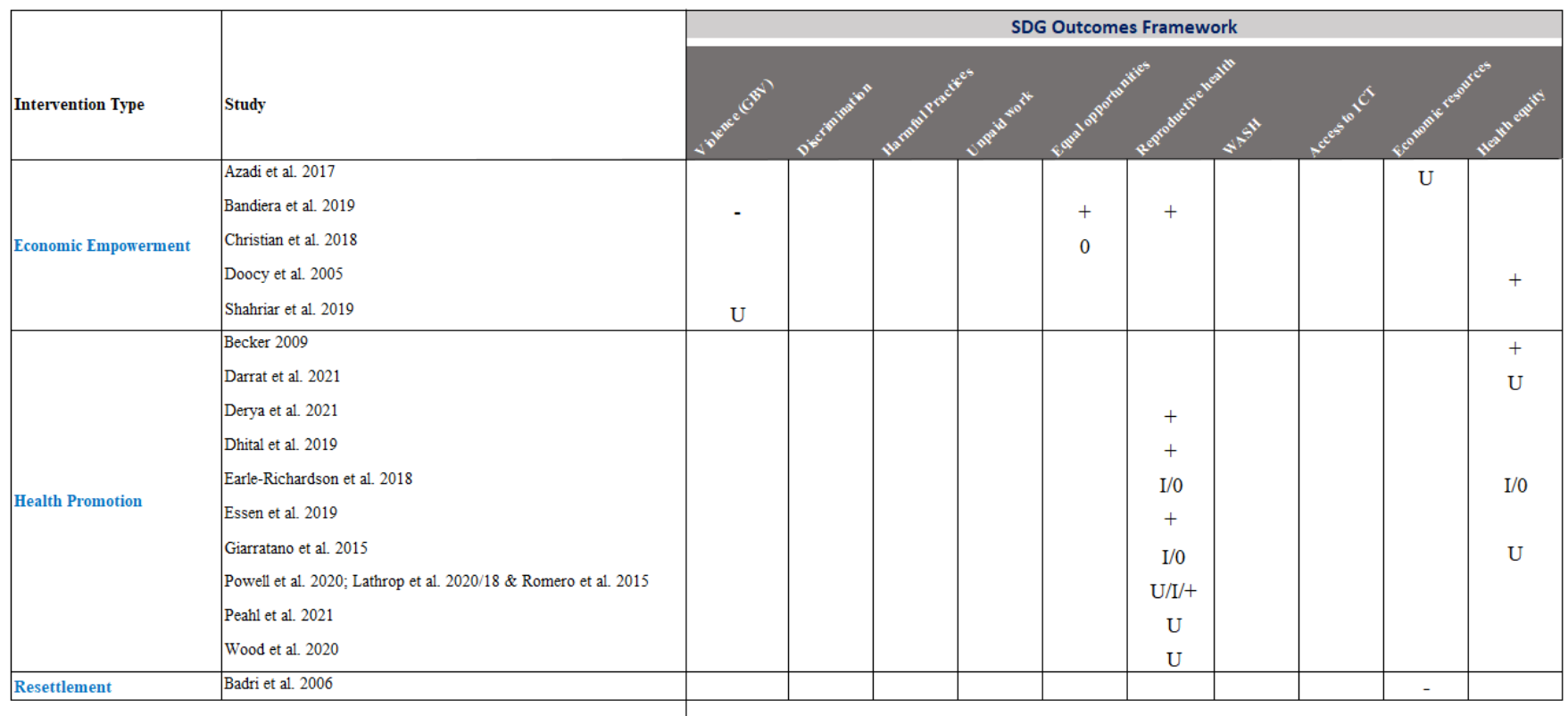

Figure 3 Summary of intervention effects by outcome type. SDG, Sustainable Development Goal. 


\section{Programme uptake, implementation and results}

\section{Economic empowerment}

The identified economic empowerment interventions sought to promote gender equality in five outcome domains: (1) gender-based violence, (2) equal opportunities, (3) reproductive health, (4) access to economic resources and (5) health equity (see figure 3 ).

Azadi and colleagues assessed the uptake of a food aid programme among 479 residents in Tigray, Northern Ethiopia, using a case-control design. ${ }^{59}$ The authors reported higher membership rates among women, with $55 \%$ of female respondents receiving food aid compared with $46 \%$ of male respondents. However, it remains unclear whether the differences in uptake were due to higher programme uptake among women or due to a higher baseline level of food insecurity among women. Because the study did not specify membership criteria or how households and individuals were sampled, the estimated uptake may be due to selection bias rather than true membership differences between men and women. The study did not examine food security or wider aspects of women's economic well-being.

The 'Empowerment and Livelihood for Adolescents' (ELA) intervention implemented in Sierra Leone was successful in alleviating some of the negative impacts that the Ebola crisis had on girls' equal opportunities: in randomly assigned treatment villages, $8 \%$ of girls (aged 12-25 years) had dropped out of school, compared with $16 \%$ in control villages. Likewise, literacy and numeracy levels were higher for girls in treatment villages. ${ }^{31}$ Further, the rate of girls engaged in child labour in the aftermath of the Ebola epidemic rose by $6 \%$ in treatment villages compared with $20 \%$ in control villages. The ELA intervention also generated beneficial impacts on reproductive health outcomes, including increases in girls' condom use and a decrease in out-of-wedlock pregnancies. However, strikingly, the authors revealed harmful intervention effects on violence-related outcomes for the older age group. For the ELA intervention, the authors observed an increase in the prevalence of unwanted sex (by 5.3 percentage points) and transactional sex (by 5.4 percentage points) among women aged 18-25 years in villages that experienced high disruption due to the Ebola crisis, compared with women in control villages. ${ }^{31}$

Christian and colleagues assessed, in a natural experiment, whether the Odisha Rural Livelihoods Programme, consisting of self-help microcredit networks, mitigated some of the devastating economic impacts of the cyclone in Bengal, India. The analysis revealed the programme had no impact on households' food expenditures but may have partly cushioned some of the cyclone's negative effects on household expenditures. Specifically, women who participated in the self-help groups experienced smaller reductions in expenditures on women's and children's goods. Postcyclone civic and political engagement did not differ for women who were part of the microcredit network. $^{56}$
The microfinance programme in Ethiopia evaluated in a cross-sectional study by Doocy and colleagues showed improvements in health equity in the context of droughts. Specifically, the odds of acute malnourishment among women in control communities were three times as high $(\mathrm{OR}=3.2,95 \%$ CI 1.1 to 9.8$)$ compared with the odds of women who were established microfinance clients. The authors also note that the programme appeared to benefit female clients more than male clients. The likelihood that male clients had received food aid in the past year was twice as high relative to female clients, suggesting that the microfinance intervention substantially reduced women's vulnerability to drought and food insecurity. ${ }^{57}$

Lastly, Shahriar and Shepherd analysed uptake of a microcredit programme targeted at low-income women in Bangladesh using a case-control design. The authors surveyed women who were first-time loan recipients and found that, among all women, experiencing domestic violence was associated with lower odds of initiating a new business venture via reduced entrepreneurial self-efficacy and fear of business failure. The authors further found that the magnitude of these associations was larger for women who had recently experienced a PHE (flood, river bank erosion or cyclone in the last 12 months) compared with those who had not. The authors concluded therefore that the negative association between domestic violence and women's entrepreneurial activities (ie, their usage of the microloan) was exacerbated by environmental disasters. However, it should be noted that the authors did not provide the results of a direct comparison of these differential associations (ie, the interaction effect), limiting inferences around the magnitude of the differences by PHE exposure. ${ }^{58}$

\section{Health promotion}

Nine health promotion interventions that we identified were focused on the domain of sexual and reproductive health. A community engagement health promotion intervention in Nepal resulted in improvements in women's maternal health knowledge and healthcare seeking behaviour based on a case-control evaluation. ${ }^{61}$ For instance, the rate of institutional deliveries as well as antenatal care visits was higher among mothers sampled postintervention than in the group sampled before the intervention. ${ }^{61}$ However, the analysis relied on two different samples at baseline and follow-up, whereby the latter sample had a higher proportion of mothers who scored better on a wealth index, which may have biased these comparisons.

Three cross-sectional studies assessed reproductive health outcomes in the context of the Zika epidemic. Earle-Richardson et al reported an assessment of four different interventions strategies to increase Zika prevention behaviours, including personal and home protection behaviours. ${ }^{63}$ The study found mixed results for the interventions, which included a Zika orientation, the provision of prevention kits, a public awareness campaign and an offer of free residential mosquito spraying services. 
Personal protective behaviours including bed net, mosquito repellent and condom use were increased by exposure to interventions, while the offer of free spraying increased home or yard spraying but not other home protection behaviours. Exposure to the different interventions varied, with $93 \%$ of pregnant women surveyed reporting exposure to orientation, $75 \%$ to kit distribution, $51 \%$ to the awareness campaign and $68 \%$ to free residential spraying. The reproductive health training delivered to women with a recent live birth in Puerto Rico resulted in higher condom use during pregnancy among women who had received prenatal provider counselling for Zika virus infection prevention. ${ }^{62}$ The Zika Contraception Access Network was successful in reaching large populations of women with modern contraceptive (long-acting reversible contraceptive (LARC)) methods and social media health communication, securing a high level of user satisfaction and access to LARC removal. ${ }^{53-55}$ Reach of the Zika Contraception Access Network was highest if awareness and information messages were delivered via Facebook. ${ }^{64}$

The 'New Orleans Healthy Start' prenatal care programme, delivered after Hurricane Katrina, showed evidence of successful implementation: a greater proportion of pregnant women who engaged in the programme reported learning about each of the 11 components of prenatal care (eg, smoking) compared with those who accessed traditional prenatal care. ${ }^{60}$ These two groups of women did not differ in their reported satisfaction of their prenatal care (eg, regarding waiting time). Women who engaged in the Healthy Start programme were, in general, a higher-risk group, including reporting worse hurricane experiences and more post-traumatic stress. Giarratano et al did not find evidence of an effect of the Healthy Start programme on a variety of prenatal or postnatal outcomes, from birth weight to gestational diabetes. This was interpreted as a programmatic success, given the higher risk among Healthy Start mothers; however, the study was designed to identify programme benefits, not non-inferiority. ${ }^{60}$

One case-control study evaluated a psychosocial intervention that was targeted at female survivors of the tsunami disaster in India. ${ }^{68}$ In affected communities, trained community workers delivered group sessions to female survivors who were encouraged to share their experiences and learn relaxation exercises. The intervention was associated with significant reductions in symptoms of psychological distress. Specifically, women who participated in the programme had 25\% lower scores on the Impact of Event Scale compared with women who had not participated.

Four interventions consisted of telehealth or e-health approaches that were implemented and scaled up in the context of the COVID-19 pandemic. One telehealth intervention was delivered to patients in a department of otolaryngology-head and neck surgery in Detroit, USA. Using a cohort study design, the authors found that female patients were more likely than male patients to take up virtual visits $(\mathrm{OR}=1.71,95 \%$ CI 1.11 to 2.63$) .{ }^{65}$ Another telehealth intervention was focused on prenatal care and targeted 96 pregnant women in Turkey, reporting significant drops in prenatal distress $(\mathrm{p}=0.008)$ and pregnancyrelated anxiety $(\mathrm{p}<0.001)$ when comparing women who participated in the telehealth intervention with those in a control group. ${ }^{52}$ Another cross-sectional study assessed uptake of and engagement with a virtual prenatal care programme among 253 pregnant women in the USA, finding that $77.5 \%$ of participants were generally satisfied with the virtual care visits; $64.8 \%$ perceived the virtual visits as equally safe as in-person visits; and $36.1 \%$ had purchased a blood pressure cuff to take their measures at home. ${ }^{67} \mathrm{~A}$ final telehealth intervention was targeted at 331 adolescents in the USA and took a broader focus on diverse health topics. With regard to gender-relevant outcomes, the cross-sectional study revealed that in $22 \%$ of all scheduled visits, adolescents sought help and advice on contraception or menstrual disorders, and in $6 \%$ of visits, they sought advice on HIV treatment. ${ }^{66}$

\section{Resettlement}

The case-control study by Badri and colleagues evaluated the outcomes of a planned resettlement programme that was implemented during the reconstruction period after the Manjil earthquake in Iran. ${ }^{69}$ Drawing on data collected 11 years after the earthquake, the authors reveal that the resettlement policy hampered employment prospects of women who were hit by the earthquake and forced to relocate to another village. However, it needs to be cautioned that the authors present neither point estimates nor corresponding CI for female employment rates, which makes a more detailed quantitative comparison of women in host communities and women in resettled communities impossible.

\section{Study designs and quality appraisal}

Included studies varied substantially with regard to their research design and methodological approach to data analysis (see figure 4). Causal inference about the intervention was reliable only in three studies, two of which were set up as cluster randomised controlled trials ${ }^{3152}$ and one as a natural experiment, exploiting variation in the intensity with which communities were hit by a cyclone as well as the staggered roll-out of a microcredit intervention. ${ }^{56}$ Five studies relied on cohort or casecontrol designs to partly control for systematic variation in exposure to the intervention of interest, ${ }^{53} 61656869$ and eight studies relied on cross-sectional, uncontrolled designs. ${ }^{54} 55575960636667$ In five studies, participants were recruited based on random sampling procedures. ${ }^{3156586263}$ Four studies relied on convenience sampling, ${ }^{606168}$ and three studies did not provide sufficient information on the sampling procedure. ${ }^{57} 5969$ Nine out of 16 studies provided detailed descriptions on the survey instruments and reported on using validation procedures to adapt the questionnaire to the local context and language, or used previously validated psychometric scales. ${ }^{52}$ 57-60 65-68 


\begin{tabular}{|c|c|c|c|c|c|}
\hline Research Design & Study & Sampling & Measurement Procedures & Statistical Analysis -Type & Adjusted \\
\hline \multirow{3}{*}{ Experimental/quasi-experimental studies } & Bandiera et al. 2019 & Random sampling & Susceptible to measurement error & ANCOVA & yes \\
\hline & Christian et al. 2018 & Random sampling & Insufficient reporting & Triple difference-in-difference & yes \\
\hline & Deray et al. 2021 & Non-probability sampling & Good quality & T-Test & no (but balanced groups) \\
\hline \multirow{5}{*}{ Non-randomised controlled studies } & Badri et al. 2006 & Insufficient reporting & Insufficient reporting & Frequency comparisons, point estimates only & no \\
\hline & Becker 2009 & Convenience sampling & Good quality & T-tests comparing pre- and post-test data & yes \\
\hline & Darrat et al. 2021 & $\begin{array}{l}\text { Full sample of patients in } \\
\text { specific care department }\end{array}$ & Good quality & Multivariate logistic regression & yes \\
\hline & Dhital et al. 2019 & Convenience sampling & Susceptible to measurement error & Chi-square tests \& multivariate logistic regression & yes \\
\hline & Shahriar et al. 2019 & Random sampling & Good quality & Moderated mediation regression & yes \\
\hline \multirow{8}{*}{ Cross-sectional } & Azadi et al. 2017 & Insufficient reporting & Good quality & Frequency comparisons, point estimates only & no \\
\hline & Doocy et al. 2005 & Insufficient reporting & Good quality & Multivariate logistic regression & yes \\
\hline & Earle-Richardson et al. 2018 & Random sampling & Susceptible to measurement error & Multivariate logistic regression & yes \\
\hline & Essen et al. 2019 & Random sampling & Susceptible to measurement error & ANOVA & yes \\
\hline & Giarratano et al. 2015 & Convenience sampling & Good quality & $\begin{array}{l}\text { Chi-square tests \& t-tests \& multivariate linear and } \\
\text { logistic regression }\end{array}$ & yes \\
\hline & $\begin{array}{l}\text { Powell 2020; Lathrop et al. } \\
2020,2018 \text { \& Romero et al. }\end{array}$ & $\begin{array}{l}\text { Clinics: Full sample / Survey: } \\
\text { Convenience sampling }\end{array}$ & $\begin{array}{l}\text { Medium quality (no validation/pre-testing } \\
\text { of measures) }\end{array}$ & Frequency comparisons, point estimates only & no \\
\hline & Peahle et al. 2021 & $\begin{array}{l}\text { Selective sample of patients } \\
\text { participating in online survey }\end{array}$ & Good quality & Frequency comparisons, point estimates only & no \\
\hline & Wood et al. 2020 & Insufficient reporting & Good quality & Frequency comparisons, point estimates only & no \\
\hline
\end{tabular}

Figure 4 Quality appraisal. ANCOVA, analysis of covariance; ANOVA, analysis of variance.

Conversely, in four studies, we judged outcome measures to be susceptible to measurement error, either due to an increased risk of social desirability bias for self-reported behaviours (eg, condom use) in a face-to-face interview, ${ }^{31}$ recall bias (eg, time use) or failure to use (or report on using) validated or prepiloted scales. ${ }^{61-63}$ There was also considerable heterogeneity between studies in terms of statistical rigour: three studies did not present the corresponding SDs, SEs or CIs to their effect estimates, and three studies presented only unadjusted outcome analyses. $^{53-555969}$

\section{DISCUSSION}

In this rapid scoping review, we sought to identify scientific evidence on strategies for promoting gender equality during PHEs. In view of the multidimensional detrimental impacts that PHEs can have on female empowerment and on women's societal status, this rapid scoping review reveals important evidence gaps. Notably, none of our included studies examined interventions that targeted sanitation and hygiene management, harmful practices (eg, child marriage), workplace or other forms of discrimination, or unpaid (care) work. More research on how to promote gender equity in these domains during PHEs is urgently needed, especially in light of the ongoing COVID-19 pandemic and its devastating socioeconomic consequences worldwide. In addition, although the search string was set up to move beyond the gender binary, none of the identified studies specifically targeted gender diverse or sexual minority participants. Hence, there is a dearth of evidence on how to effectively protect LGBTQIA* populations in the context of PHEs.

The studies that we have identified in this rapid scoping review highlighted positive associations between these interventions and women's and girls' sexual and reproductive health, ${ }^{31}{ }^{53-55} 61$ educational opportunities, ${ }^{31}$ economic welfare ${ }^{31}$ and health equity in terms of (mal) nutrition. ${ }^{57}$

Two intervention strategies showed promise with regard to promoting gender equality during and after PHEs. First, two evaluation studies ${ }^{53-55} 63$ presented largescale governmental efforts for promoting sexual and reproductive health in the context of the Zika pandemic in Puerto Rico. Such efforts could be scaled up to other countries and may also be highly relevant in the context of PHEs other than Zika. In view of the increasing rate of teenage pregnancies in the aftermath of previous PHEs, ${ }^{32}$ ensuring uninterrupted access to modern contraceptives should be considered one of the key policy priorities. In response to lockdown orders, telehealth offers appear to be promising intervention strategies and have shown high levels of uptake and user satisfaction in the context of the COVID-19 pandemic. ${ }^{52}{ }^{65-67}$ Previous studies have already pointed to the suitability of telehealth interventions for supporting maternal care and women's and girls' sexual and reproductive health outside of public health emergencies. ${ }^{72}$ As these services are scaled up in response to the COVID-19 pandemic, it is crucial that these are gendersensitive and that sex-segregated outcomes are included for monitoring and evaluation purposes. ${ }^{73}$ Second, economic empowerment programmes may be a crucial strategy for securing women's and girls' livelihoods in emergency settings. The impact of such programmes can go beyond economic aspects and may also decrease the risk of harmful coping behaviours such as marrying off a young daughter to receive a bride-price,$^{33}$ selling productive assets ${ }^{74}$ or engaging in risky sexual behaviour. ${ }^{75}$ One of the most widely used and promising tools to cushion the economic shock induced by a PHE are unconditional cash transfers. A rigorous evidence base has already been established, suggesting that unconditional cash transfers, in general, can improve food security, cognitive and physical child development, and stipulate business activities 
and educational attainment. ${ }^{76} 77$ It is important to note that the gendered impacts of PHEs can vary substantially between cultural, political and economic contexts, and thus between high-income and low-income countries. However, the COVID-19 pandemic has jeopardised gender equality worldwide and has also put a high burden on women in high-income countries that have successfully narrowed their gender gap in recent years. ${ }^{4}$ Based on the evidence discussed in this rapid scoping review, there are important learnings to transport from low-income and middle-income to high-income countries. A first key lesson is the prioritisation of equitable access to services, including sexual and reproductive healthcare. ${ }^{53-55} \mathrm{~A}$ second is the emphasis on women's economic empowerment, which, in higher-income settings, may focus mostly on extended access to childcare services, uninterrupted income flows, and higher flexibility in working hours and project deadlines. ${ }^{78}$ However, it needs to be cautioned that a 'one-size-fits-all' approach does not exist and that more research on how to protect women's and girls' integrity and rights in the context of PHEs in both highincome and low-income countries is urgently needed.

The lack of evidence demonstrated by this rapid scoping review likely reflects the associated risks and difficulties of conducting research and collecting data in PHE settings. Yet, our synthesis demonstrates that wellintended interventions may sometimes have unintended consequences and even induce harm. It is therefore essential that emergency mitigation efforts are accompanied by thorough monitoring and evaluation efforts and integrate feedback systems to stop or modify (unintended) harmful approaches and improve programme response. It is also important that rigorous monitoring and evaluation is applied to gender equality programmes delivered by different policy agents-including philanthropic organisations, larger international organisations as well as national governments-so as to better understand which actors can most effectively intervene, and at which level. Indeed, one of the identified interventions reported a significant increase in violence against women, at least for some programme beneficiaries, postintervention. ${ }^{31}$ This corroborates previous evidence documenting that economic empowerment programmes may expose female beneficiaries to a higher risk of violence. ${ }^{79} 80$ To this end, promising mitigation strategies in delivering economic strengthening programmes have included adding specific training and awareness raising on gender roles and stereotypes and engaging male spouses in these programme components. ${ }^{79} 81-83$ Given the rarity of being able to exploit random variation in PHE settings, these efforts should include, wherever possible, measuring key confounders of the programme-outcome association (which can be determined in times of non-emergencies and based on existing literature) as well as using appropriate measurement procedures, including appropriately trained interviewers, safe and secure data collection and storage, and validated instruments. While causality is difficult to establish in the absence of experimental designs, rich qualitative data as well as mixed-methods analyses can help depict the channels through which a programme may induce improvements in gender equality outcomes.

A number of limitations are noteworthy. First, our search strategy was set up with English search terms only and non-English publications were excluded. Second, in light of the ongoing COVID-19 pandemic and the immediate demand for evidence-based policy strategies, we prioritised rapid evidence generation over a more systematic search by focusing only on published studies. Therefore, it is possible that our rapid scoping review did not capture some eligible programmes that were available only in grey literature outlets. Third, while we categorise reported coefficients for any of the intervention-outcome association as positive $(+)$, negative $(-)$ and neutral $(0)$, they should not be interpreted as causal. Thirteen out of 16 included studies were based on research designs that did not allow for causal inference on the intervention impacts. Lastly, we did not include qualitative data in this rapid scoping review in order to prioritise evidence with conclusions on intervention effectiveness. However, this is a valuable direction for future inquiry, to generate further insights into the mechanisms of change underlying effective programmes or into the facilitating and inhibiting factors that explain interventions' successes and failures.

\section{CONCLUSION}

The current COVID-19 pandemic with its 'triple hit to health, education and income' is projected to severely slow down progress towards realising the SDGs by $2030 .{ }^{84}$ The SDG5 for 'gender equality' is no exception, as emphasised by UN Secretary-General António Guterres: 'Limited gains in gender equality and women's rights made over the decades are in danger of being rolled back due to the COVID-19 pandemic' ${ }^{85}$ Findings from this rapid scoping review provide preliminary support for economic empowerment programmes and focused sexual and reproductive health to promote gender equality in the domains of sexual and reproductive health, ${ }^{3153-556162}$ equal opportunities ${ }^{31}$ and health equity. ${ }^{6870}$ However, this rapid scoping review also uncovers important evidence gaps across all outcome domains of gender equality, particularly with regard to the (1) prevention of harmful practices, (2) adequate WASH management, (3) women's time use and care burden, (4) workplace and other discrimination, and (5) access to technologies and economic resources. Concerted monitoring and evaluation efforts in PHE settings are urgently needed to inform responsive and effective policy programmes.

Twitter Janina I Steinert @jisteinert and Caterina Alacevich @CateAlacevich

Acknowledgements We are grateful for funding from the Joachim Herz Foundation, the Social Sciences and Humanities Research Council of Canada and the Canadian Institutes of Health Research. 
Contributors JIS, ARY, CA and JH conceptualised the study and developed the review protocol. BS ran the database searches. JIS drafted the first version of the manuscript and ARY, CA, BS and JH provided substantial revisions and feedback. All authors screened abstracts and titles, extracted and analysed the data with feedback from all authors, and read and approved the final version of the manuscript.

Funding JS is supported by the Joachim Herz Foundation. BS is supported by the Social Sciences and Humanities Research Council of Canada. AY is supported by the Canadian Institutes of Health Research (HSI-166388)

Map disclaimer The inclusion of any map (including the depiction of any boundaries therein), or of any geographical or locational reference, does not imply the expression of any opinion whatsoever on the part of BMJ concerning the legal status of any country, territory, jurisdiction or area or of its authorities. Any such expression remains solely that of the relevant source and is not endorsed by BMJ. Maps are provided without any warranty of any kind, either express or implied.

Competing interests None declared.

Patient consent for publication Not required.

Provenance and peer review Not commissioned; externally peer reviewed.

Data availability statement All review material including data extraction sheets and search strings will be made available via https://osf.io/8hkfd/ Reviewer registration can also be found here: DOI 10.17605/OSF.IO/8HKFD

Supplemental material This content has been supplied by the author(s). It has not been vetted by BMJ Publishing Group Limited (BMJ) and may not have been peer-reviewed. Any opinions or recommendations discussed are solely those of the author(s) and are not endorsed by BMJ. BMJ disclaims all liability and responsibility arising from any reliance placed on the content. Where the content includes any translated material, BMJ does not warrant the accuracy and reliability of the translations (including but not limited to local regulations, clinical guidelines, terminology, drug names and drug dosages), and is not responsible for any error and/or omissions arising from translation and adaptation or otherwise.

Open access This is an open access article distributed in accordance with the Creative Commons Attribution Non Commercial (CC BY-NC 4.0) license, which permits others to distribute, remix, adapt, build upon this work non-commercially, and license their derivative works on different terms, provided the original work is properly cited, appropriate credit is given, any changes made indicated, and the use is non-commercial. See: http://creativecommons.org/licenses/by-nc/4.0/.

ORCID iD

Janina I Steinert http://orcid.org/0000-0001-7120-0075

\section{REFERENCES}

1 Johns Hopkins University. COVID-19 Dashboard by the center for systems science and engineering (CSSE), 2020. Available: https:// coronavirus.jhu.edu/map.html

2 Wenham C, Smith J, Morgan R, et al. COVID-19: the gendered impacts of the outbreak. Lancet 2020;395:846-8.

3 Fraser DE. Impact of COVID-19 pandemic on violence against women and girls. 16, 2020.

4 Alon T, Doepke M, Olmstead-Rumsey J. The impact of COVID-19 on gender equality. Germany: University of Bonn and University of Mannheim, 2020. https://ideas.repec.org/p/bon/boncrc/crctr224 2020_163.html

5 World Health Organization. Glossary of humanitarian terms, 2008. Available: https://www.who.int/hac/about/reliefweb-aug2008.pdf? $\mathrm{ua}=1$

6 Felten-Biermann C. Gender and natural disaster: sexualized violence and the tsunami. Development 2006;49:82-6.

7 Davies SE, Bennett B. A gendered human rights analysis of ebola and zika: locating gender in global health emergencies. Int Aff 2016;92:1041-60.

8 Peterman A, Potts A, O'Donnell M. Pandemics and violence against women and children, 2020.

9 Rao S. A natural disaster and intimate partner violence: evidence over time. Soc Sci Med 2020;247:112804.

10 First JM, First NL, Houston JB. Intimate partner violence and disasters: a framework for empowering women experiencing violence in disaster settings. Journal of Women \& Social Work 2017;32:390-403.

11 O'Brien M, Tolosa MX. The effect of the 2014 West Africa Ebola virus disease epidemic on multi-level violence against women. Int J Hum Rights Healthc 2016;9:151-60.
12 Karamouzian M, Hategekimana C. Ebola treatment and prevention are not the only battles: understanding Ebola-related fear and stigma. Int J Health Policy Manag 2015;4:55-6.

13 Armbruster S, Klotzbücher V. Lost in lockdown? COVID-19, social distancing, and mental health in Germany. Diskussionsbeiträge, 2020. Available: https://www.econstor.eu/handle/10419/218885 [Accessed 14 Dec 2020].

14 Chandan JS, Taylor J, Bradbury-Jones C. COVID-19: a public health approach to manage domestic violence is needed. Lancet Public Health (Published Online First: 8 May 2020).

15 Leslie E, Wilson R. Sheltering in place and domestic violence: evidence from calls for service during COVID-19. J Public Econ 2020;189:104241.

16 Ravindran S, Shah M. Unintended consequences of Lockdowns: COVID-19 and the shadow pandemic. National Bureau of Economic Research 2020.

17 Peterman A, O'Donnell M. COVID-19 and violence against women and children: a second research round up, 2020.

18 Yakubovich AR, Stöckl H, Murray J, et al. Risk and protective factors for intimate partner violence against women: systematic review and meta-analyses of Prospective-Longitudinal studies. Am J Public Health 2018;108:e1-11.

19 Schneider D, Harknett K, McLanahan S. Intimate partner violence in the great recession. Demography 2016;53:471-505.

20 Hall KS, Samari G, Garbers S, et al. Centring sexual and reproductive health and justice in the global COVID-19 response. Lancet 2020;395:1175-7.

21 Sochas L, Channon AA, Nam S. Counting indirect crisis-related deaths in the context of a low-resilience health system: the case of maternal and neonatal health during the Ebola epidemic in Sierra Leone. Health Policy Plan 2017;32:iii32-9.

22 McGinn T. Reproductive health of war-affected populations: what do we know? Int Fam Plan Perspect 2000;26:174-80.

23 Bloom-Feshbach K, Simonsen L, Viboud C, et al. Natality decline and miscarriages associated with the 1918 influenza pandemic: the Scandinavian and United States experiences. J Infect Dis 2011;204:1157-64.

24 Wong SF, Chow KM, Leung TN, et al. Pregnancy and perinatal outcomes of women with severe acute respiratory syndrome. Am J Obstet Gynecol 2004;191:292-7.

25 Nanda K, Lebetkin E, Steiner MJ, et al. Contraception in the era of COVID-19. Glob Health Sci Pract 2020;8:166-8.

26 Rissa-Gill I, Finnegan L. Children's ebola recovery assessment: sierra leone, save the children, 2015

27 UNICEF. Monitoring and mitigating the secondary impacts of the coronavirus disease (COVID-19) pandemic on wash services availability and access, 2020. Available: https://www.unicef. org/documents/monitoring-and-mitigating-secondary-impactscoronavirus-disease-covid-19-pandemic-wash

28 Hennegan J, Shannon AK, Rubli J, et al. Women's and girls' experiences of menstruation in low- and middle-income countries: a systematic review and qualitative metasynthesis. PLoS Med 2019;16:e1002803.

29 Fuhrman S, Kalyanpur A, Friedman S, et al. Gendered implications of the COVID-19 pandemic for policies and programmes in humanitarian settings. BMJ Glob Health 2020;5:e002624.

30 UN Women. Covid-19 and violence against women and girls: addressing the shadow pandemic.

31 Bandiera O, Buehren N, Goldstein M. The economic lives of young women in the time of ebola: lessons from an empowerment program, 2019: 80.

32 Burzynska K, Contreras G. Gendered effects of school closures during the COVID-19 pandemic. Lancet 2020;395:395.

33 Corno L, Hildebrandt N, Voena A. Age of marriage, weather shocks, and the direction of marriage payments. Econometrica 2020;88:879-915.

34 Fawole O, Bamiselu O, Adewuyi P, et al. Gender dimensions to the Ebola outbreak in Nigeria. Ann Afr Med 2016;15:7-13.

35 Del Boca D, Oggero N, Profeta P. Women's and men's work, housework and childcare, before and during COVID-19. Rev Econ Household (Published Online First: 6 September 2020).

36 Boca DD, Oggero N, Profeta P. Women's work, housework, and childcare before and during COVID-19. VoxEU.org, 2020. Available: https://voxeu.org/article/women-s-work-housework-and-childcareand-during-covid-19 [Accessed 14 Dec 2020].

37 Sevilla A, Smith S. Baby steps: the gender division of childcare during the COVID-19 pandemic, 2020. Available: https://www.iza org/publications/dp/13302/baby-steps-the-gender-division-ofchildcare-during-the-covid-19-pandemic

38 International Labour Organisation. Impact of the COVID-19 crisis on loss of jobs and hours among domestic workers, 2020. 
39 International Labour Organisation. Women and men in the informal economy: a statistical brief, 2019.

40 Williamson EJ, Walker AJ, Bhaskaran K, et al. Factors associated with COVID-19-related death using OpenSAFELY. Nature 2020;584:430-6.

41 Akseer N, Kandru G, Keats EC, et al. COVID-19 pandemic and mitigation strategies: implications for maternal and child health and nutrition. Am J Clin Nutr 2020;112:251-6.

42 Fawole OI, Bamiselu OF, Adewuyi PA, et al. Gender dimensions to the Ebola outbreak in Nigeria. Ann Afr Med 2016;15:7-13.

43 Boniol M, Mclsaac M, Xu L. Gender equity in the health workforce: analysis of 104 countries. WHO, 2019.

44 Ryan NE, El Ayadi AM. A call for a gender-responsive, intersectional approach to address COVID-19. Glob Public Health 2020;15:1404-12.

45 Steinert J, Alacevich C, Hennegan J, et al. Response strategies for gender equality in public health emergencies: a rapid evidence assessment and systematic review.

46 Dobbins M. Rapid review guidebook: steps for conducting a rapid review. Hamilton. ON: National Collaborating Centre for Methods and Tools, 2017.

47 Haffajee R, Parmet WE, Mello MM. What Is a Public Health "Emergency"? N Engl J Med Overseas Ed 2014;371:986-8.

48 Nelson C, Lurie N, Wasserman J, et al. Conceptualizing and defining public health emergency preparedness. Am J Public Health 2007;97 Suppl 1:S9-11.

49 Craig P, Dieppe P, Macintyre S, et al. Developing and evaluating complex interventions: the new medical Research Council guidance. BMJ 2008:337:a1655

50 Amrhein V, Greenland S, McShane B. Scientists rise up against statistical significance. Nature 2019;567:305-7.

51 Wasserstein RL, Schirm AL, Lazar NA. Moving to a world beyond "p. Am Stat 2019;73:1-19.

52 Aksoy Derya Y, Altiparmak S, AkÇa E, et al. Pregnancy and birth planning during COVID-19: the effects of tele-education offered to pregnant women on prenatal distress and pregnancy-related anxiety. Midwifery 2021:92:102877.

53 Lathrop E, Hurst S, Mendoza Z, et al. Final program data and factors associated with long-acting reversible contraception removal: the Zika contraception access network. Obstet Gynecol 2020;135:1095-103.

54 Lathrop E, Romero L, Hurst S, et al. The zika contraception access network: a feasibility programme to increase access to contraception in puerto rico during the 2016-17 zika virus outbreak. Lancet Public Health 2018;3:e91-9.

55 Romero L, Koonin LM, Zapata LB, et al. Contraception as a medical countermeasure to reduce adverse outcomes associated with Zika virus infection in Puerto Rico: the Zika contraception access network program. Am J Public Health 2018;108:S227-30.

56 Christian P, Eeshani K, Nethra P. Safety nets and natural disaster mitigation: evidence from cyclone Phailin in Odisha 2018:30.

57 Doocy S, Teferra S, Norell D, et al. Credit program outcomes: coping capacity and nutritional status in the food insecure context of Ethiopia. Soc Sci Med 2005;60:2371-82.

58 Shahriar AZM, Shepherd DA. Violence against women and new venture initiation with microcredit: self-efficacy, fear of failure, and disaster experiences. J Bus Ventur 2019;34:105945.

59 Azadi H, De Rudder F, Vlassenroot K, et al. Targeting international food aid programmes: the case of productive safety net programme in Tigray, Ethiopia. Sustainability 2017;9:1716.

60 Giarratano G, Harville EW, Barcelona de Mendoza V, de Mendoza VB, et al. Healthy start: description of a safety net for perinatal support during disaster recovery. Matern Child Health J 2015;19:819-27.

61 Dhital R, Silwal RC, Simkhada P, et al. Assessing knowledge and behavioural changes on maternal and newborn health among mothers following post-earthquake health promotion in Nepal. PLOS One 2019;14:e0220191.

62 Salvesen von Essen B, Kortsmit K, Warner L, et al. Preventing Sexual Transmission of Zika Virus Infection during Pregnancy, Puerto Rico, USA, 2016 ${ }^{1}$. Emerg Infect Dis 2019;25:2115-9.

63 Earle-Richardson G, Prue C, Turay K, et al. Influences of community interventions on zika prevention behaviors of pregnant women, puerto rico, july 2016-june 2017 . Emerg Infect Dis 2018;24:2251-61.

64 Powell R, Rosenthal J, August EM, et al. Ante La Duda, Pregunta: a social marketing campaign to improve contraceptive access during a public health emergency. Health Commun 2020;0:1-8

65 Darrat I, Tam S, Boulis M et al. Socioeconomic disparities in patient use of telehealth during the coronavirus disease 2019 surge. JAMA Otolaryngol Head Neck Surg 2021;147:287-95.
66 Wood SM, White K, Peebles R, et al. Outcomes of a rapid adolescent telehealth scale-up during the COVID-19 pandemic. J Adolesc Health 2020;67:172-8

67 Peahl AF, Powell A, Berlin $\mathrm{H}$, et al. Patient and provider perspectives of a new prenatal care model introduced in response to the coronavirus disease 2019 pandemic. Am J Obstet Gynecol 2021;224:384.e1-384.e11.

68 Becker SM. Psychosocial care for women survivors of the tsunami disaster in India. Am J Public Health 2009;99:654-8.

69 Badri SA, Asgary A, Eftekhari AR, et al. Post-disaster resettlement, development and change: a case study of the 1990 Manjil earthquake in Iran. Disasters 2006;30:451-68.

70 Doocy S, Teferra S, Norell D, et al. Credit program outcomes: coping capacity and nutritional status in the food insecure context of Ethiopia. Soc Sci Med 2005;60:2371-82.

71 Christian P, Kandpal E, Palaniswamy N, et al. Safety nets and natural disaster mitigation: evidence from cyclone Phailin in Odisha. Clim Change 2019;153:141-64.

72 DeNicola N, Grossman D, Marko K, et al. Telehealth interventions to improve obstetric and gynecologic health outcomes: a systematic review. Obstet Gynecol 2020;135:371-82.

73 Monaghesh E, Hajizadeh A. The role of telehealth during COVID-19 outbreak: a systematic review based on current evidence. BMC Public Health 2020;20:1-9.

74 Orkin K. The evidence behind putting money directly in the pockets of the poor, 2020. Available: https://www.ox.ac.uk/news/scienceblog/evidence-behind-putting-money-directly-pockets-poor

75 Pronyk PM, Hargreaves JR, Kim JC, et al. Effect of a structural intervention for the prevention of intimate-partner violence and HIV in rural South Africa: a cluster randomised trial. Lancet 2006;368:1973-83.

76 Baird S, McKenzie D, Özler B. The effects of cash transfers on adult labor market outcomes. IZA Journal of Development and Migration 2018;8:22.

77 Evans DK, Hausladen S, Kosec K. Community-Based Conditional Cash Transfers in Tanzania : Results from a Randomized Trial. The World Bank, 2014. https://ideas.repec. org/cgi-bin/htsearch?ul=\&q=\%28saving++\%7C+micro-saving $+\% 7$ Cmicrosaving $+\% 7 \mathrm{C}+$ Aflatoun $+\% 7 \mathrm{C}+$ YouthSafe $+\%$ $29+\% 2 \mathrm{~B}+\% 28 \% \mathrm{E} 2 \% 80 \% 9$ Crandomized +control ${ }^{*}+$ trial\%E2\%80\%9D+\%7C++\%E2\%80\%9Crandomised+control $^{*}+$ trial $\%$ E2\% $80 \% 9 \mathrm{D}+\% 7 \mathrm{C}++$ randomised $+\% 7 \mathrm{C}++$ randomized $+\% 7 \mathrm{C}++\mathrm{RCT}+\% 7 \mathrm{C}+++$ trial $+\% 7 \mathrm{C}+$ experiment $^{*}+\% 29+\& \mathrm{cmd}=$ Search $\% 21 \& w f=4 B F F \& s=R \& d t=r a n g e \& d$ $\mathrm{b}=01 \% 2 \mathrm{~F} 01 \% 2 \mathrm{~F} 1990 \& \mathrm{de}=\& \mathrm{~m}=$ all\&fmt $=$ long \&sy $=1 \& \mathrm{ps}=50$

78 Witteman HO, Haverfield J, Tannenbaum C. COVID-19 gender policy changes support female scientists and improve research quality. Proc Natl Acad Sci U S A 2021;118. doi:10.1073/pnas.2023476118. [Epub ahead of print: 0902 2021].

79 Eggers Del Campo I, Steinert Jl. The effect of female economic Empowerment interventions on the risk of intimate partner violence: a systematic review and meta-analysis. Trauma Violence Abuse 20 20:1524838020976088:1524838020976088.

80 Vyas S, Watts C. How does economic empowerment affect women's risk of intimate partner violence in low and middle income countries? A systematic review of published evidence. J Int Dev 2009;21:577-602.

81 Halim N, Steven Mzilangwe E, Reich N, et al. Together to end violence against women in Tanzania: results of a pilot cluster randomized controlled trial to evaluate preliminary effectiveness of interpersonal and community level interventions to address intimate partner violence. Glob Public Health 2019;14:1653-68.

82 lyengar R, Ferrari G. Comparing economic and social interventions to reduce intimate partner violence: evidence from central and southern Africa. Available: https://chicago.universitypressschol arship.com/view/10.7208/chicago/9780226316192.001.0001/upso9780226316055-chapter-6 [Accessed 14 Dec 2020].

83 Gupta J, Falb KL, Lehmann H, et al. Gender norms and economic empowerment intervention to reduce intimate partner violence against women in rural Côte d'Ivoire: a randomized controlled pilot study. BMC Int Health Hum Rights 2013;13:46.

84 Chandan JS, Taylor J, Bradbury-Jones C, et al. COVID-19: a public health approach to manage domestic violence is needed. Lancet Public Health 2020;5:e309.

85 United Nations. Goal 5: achieve gender equality and empower all women and girls - COVID-19 response, 2020. Available: https:// www.un.org/sustainabledevelopment/gender-equality/ 